\title{
Malignant Apocrine Neoplasm
}

National Cancer Institute

\section{Source}

National Cancer Institute. Malignant Apocrine Neoplasm. NCI Thesaurus. Code C6800.

A malignant neoplasm involving the apocrine gland. 